\title{
Synthesis and structural characterization of a binuclear iridium complex with bridging, bidentate $\mathrm{N}$-heterocyclic carbene coordination of $2,2^{\prime}: 6^{\prime}, 2^{\prime \prime}$-terpyridine $\dagger$
}

\author{
Margarita Paneque, Manuel L. Poveda,* Florencia Vattier, Eleuterio Alvarez \\ and Ernesto Carmona*
}

Received (in Cambridge, UK) 18th May 2009, Accepted 3rd August 2009

First published as an Advance Article on the web 18th August 2009

DOI: $10.1039 / b 909837 b$

Thermal activation of terpyridine in the presence of an unsaturated Ir(III) fragment stabilized by a hydrotris(pyrazolyl) borate ligand gives rise to mononuclear complex 2 and binuclear 3 , in which the polypyridine behaves, respectively, as a mono- or a bi-dentate N-heterocyclic carbene.

The transition metal chemistry of $2,2^{\prime}: 6^{\prime}, 2^{\prime \prime}$-terpyridine (terpy) has undergone a remarkable development in the last two decades. This is due to the importance of terpy complexes in metallosupramolecular chemistry, the special redox and photophysical properties they exhibit and their applications in other areas of chemistry like organometallic chemistry and homogeneous catalysis. ${ }^{1,2}$

Recent work has revealed that pyridines and related $\mathrm{N}$-heterocycles can undergo metal-induced rearrangements to form N-heterocyclic carbenes (NHC) ${ }^{3-9}$ Extension of initial results for 2 -substituted pyridines ${ }^{9 c}$ to $2,2^{\prime}$-bipyridine (bpy) and 1,10-phenanthroline (phen) has permitted isolation of compounds that feature monodentate, NHC-type coordination of these ligands ${ }^{9 a}$ (structures $\mathbf{A}$ and $\mathbf{B}$ in Scheme 1).
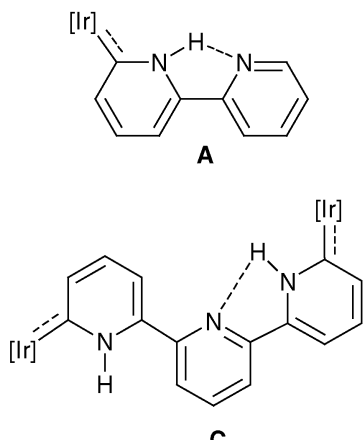

C

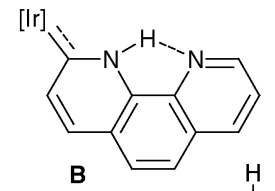

B

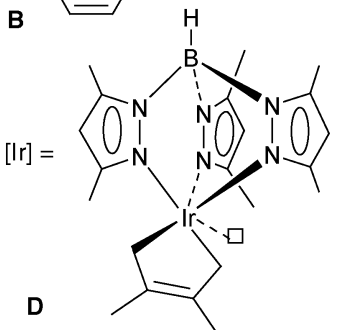

Scheme 1 Monodentate NHC coordination of bpy (A) and phen (B) and bridging bidentate NHC coordination of terpy $(\mathbf{C})$. D is the structural formula of the $\operatorname{Ir}(\mathrm{III})$ fragment in compounds $\mathbf{2}$ and $\mathbf{3}$, symbolized as [Ir] in this and other parts of this communication.

Instituto de Investigaciones Químicas, Departamento de Química Inorgánica, Consejo Superior de Investigaciones Cientificas,

Universidad de Sevilla, Avda. Américo Vespucio 49Isla de la Cartuja, Sevilla, 41092, Spain.E-mail: guzman@us.es;

Fax: + 34 95-446-0565; Tel: + 34 954-489-558

$\dagger$ Electronic supplementary information (ESI) available: Full experimental procedures and data. CCDC 731545-731547. For ESI and crystallographic data in CIF or other electronic format see DOI: $10.1039 / \mathrm{b} 909837 \mathrm{~b}$
This evidences that, when binding to highly congested Lewis acid centres, these ordinarily chelating Lewis bases may adopt the radically different $\mathrm{C}$-carbene coordination mode. Extension of these results to terpy is justified as, by and large, this molecule acts as a chelate (most commonly tridentate, although examples of bidentate $\mathrm{N}, \mathrm{N}^{\prime}$-coordination can be found at the Cambridge Crystallographic Data Centre), and monodentate $\mathrm{N}$-binding is very rare. ${ }^{10 a, b} \mathrm{Ru}$-terpy complexes with quaternized $(\mathrm{N}, \mathrm{N}, \mathrm{C})$-tridentate ligands have been structurally chraracterized by Tanaka and co-workers and may exhibit carbene (pyridinylidene) character in solution. ${ }^{10 c}$ Herein we report that terpy can give rise not only to monodentate, $\mathbf{C}$-carbene structures of type $\mathbf{A}$ or $\mathbf{B}$ in Scheme 1 but also to the unprecedented bridging dicarbene coordination shown in $\mathbf{C}$.

Similarly to reactions with other Lewis bases like $\mathrm{PMe}_{3}$ or $\mathrm{CO}$, compound $\mathrm{Tp}^{\mathrm{Me} 2} \operatorname{Ir}\left(\eta^{4}-\mathrm{CH}_{2}=\mathrm{C}(\mathrm{Me}) \mathrm{C}(\mathrm{Me})=\mathrm{CH}_{2}\right)(\mathbf{1})^{11 a}$ rearranges in the presence of terpy $\left(\mathrm{C}_{6} \mathrm{H}_{12}, 90{ }^{\circ} \mathrm{C}, 20 \mathrm{~h}\right)$ to Ir(III) complexes 2 and $\mathbf{3}$ (Scheme 2) in which the original $\eta^{4}$-diene ligand has been converted into a $\kappa^{2} C, C^{\prime}$-dialkyl group, ${ }^{11 b}$ as represented in structure $\mathbf{D}$ of Scheme 1. Use of an Ir : terpy molar ratio of $1: 2$ yields a $c a .4: 1$ mixture of monocarbene $\mathbf{2}$ and dicarbene 3 (Scheme 2), whereas under identical conditions but with a $2: 1$ proportion of $1:$ terpy the crude reaction mixture contains compounds $\mathbf{2}$ and $\mathbf{3}$ in a roughly $1: 3$ ratio. Column chromatography on silica allows isolation of pure crystalline samples of $\mathbf{2}$ and $\mathbf{3}$ in the form of bright and dark red products, respectively. Not unexpectedly reaction of $\mathbf{2}$ with a second equivalent of $\mathbf{1}$ also yields 3 .

The terpy coordination modes proposed in Scheme 2 for 2 and 3 , based on NMR spectroscopic studies $\left(\mathrm{CDCl}_{3}\right)$, find no literature precedent, hence the two compounds have been investigated by X-ray crystallography. Fig. 1 and Fig. 2 show structural representations of the molecules of the two complexes.

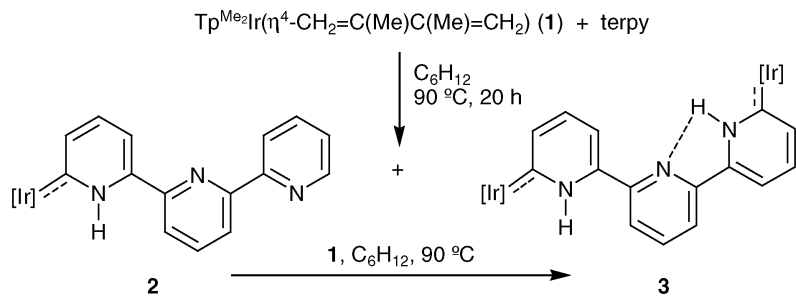

Scheme 2 Reaction of compound 1 with terpy to give mono- and bis-carbene complexes $\mathbf{2}$ and $\mathbf{3}$, respectively. 


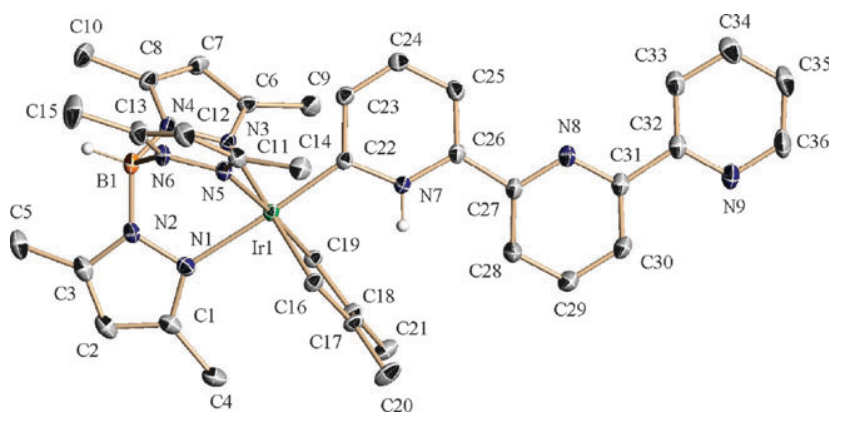

Fig. 1 Perspective view of the rotameric structure of mononuclear carbene $\mathbf{2}$ found in its monoclinic polymorph. Thermal ellipsoids are plotted at the $30 \%$ probability level. Hydrogen atoms are omitted for clarity.

For 2, two polymorphs have been isolated and characterized (see ESI $\dagger$ ). Fig. 1 corresponds to the monoclinic crystal form of $2 \ddagger$ that features a "trans-trans" conformation of the pyridine rings, whereas the other polymorph is triclinic $(P \overline{1})$ and exhibits a "cis-trans" conformation of the rings (see ESI $\dagger$ ). The two known polymorphs of the free ligand terpy exhibit the energetically favourable "trans-trans" configuration. ${ }^{12}$ In the monoclinic form (Fig. 1) the polypyridine moiety occupies a region of the space opposite to that of the $\mathrm{Tp}^{\mathrm{Me} 2}$ ligand, being similar in that regard to the structure of the analogous bpy and phen complexes. ${ }^{9 a}$ It is worth noting that the "cis" arrangement of the N(7) and N(8) rings, which would permit a beneficial $\mathrm{N}-\mathrm{H} \cdots \mathrm{N}$ hydrogen bond interaction, becomes unfavourable due to steric hindrance between the $\mathrm{N}(9)$ pyridinic ring and the enediyl ligand methyl substituents $\mathrm{C}(20)$ and $\mathrm{C}(21)$. As discussed below, this is the predominant solution structure, whereas that of the triclinic polymorph (see Fig. S1, ESI $\dagger$ ), with a "cis" $\mathrm{N}(7)-\mathrm{N}(8)$ distribution (and consequently a $\mathrm{N}-\mathrm{H} \cdots \mathrm{N}$ bond) and the $\mathrm{N}(8)$ and $\mathrm{N}(9)$ rings in the same region of space as the $\mathrm{Tp}^{\mathrm{Me} 2}$ ligand, does not appear to exist in solution in detectable amounts.
As already noted, complex $\mathbf{3} \S$ is structurally unique. Formally, it derives from $\mathbf{2}$ by incorporation of a second iridium fragment into its terminal $\mathrm{N}(9)$ ring $(\mathrm{N}(15)$ in the structure of 3, Fig. 2) that rotates around the $\mathrm{C}-\mathrm{C}$ bond to central ring, so as to permit a favourable hydrogen bond interaction with its $\mathrm{N}$ atom, $\mathrm{N}(14)$, to be created. As can be seen in Scheme 1 (structure $\mathbf{C}$ ) and Fig. 2 the pyridine rings of 3 adopt a "cis-trans" configuration, with the "cis" rings featuring a $\mathrm{N}-\mathrm{H} \cdots \mathrm{N}$ hydrogen bond interaction of length ca. $2.40 \AA$. In turn, the $\mathrm{N}-\mathrm{H}$ group of the "trans" ring participates in a hydrogen bond that now involves the $\pi$ electrons of the coordinated enediyl terminus. This interaction is characterized by a length of $c a$. $2.32 \AA$, similar to those found in related systems. ${ }^{13}$ The two Ir-C sigma bonds of each iridium moiety are identical within experimental error, with average bond lengths of 2.066(16) and 2.082(16) $\AA$. The Ir-carbene bonds are shorter than the Ir-alkyl bonds by $c a$. $0.1 \AA$ and are also identical within experimental error, with lengths of 1.947(8) and 1.951(9) $\AA$.

Whereas in mononuclear $\mathbf{2}$ the pyridine rings are nearly coplanar, with torsion angles between the central $\mathrm{N}(8)$ ring and the terminal $\mathrm{N}(7)$ and $\mathrm{N}(9)$ rings of $3.1(2)^{\circ}$ and $4.0(2)^{\circ}$, respectively, in binuclear $\mathbf{3}$ there is considerable deviation from planarity. Thus, the ring that contains $\mathrm{N}(13)$ forms a torsion angle of $38.2(3)^{\circ}$ with the central $\mathrm{N}(14) \mathrm{ring}$, while the corresponding angle for the "cis" $\mathrm{N}(15)$ ring is smaller, ca. $19.3(3)^{\circ}$. The non-coordinated rings of $\mathbf{2}$ exhibit bond lengths practically identical to those in the free ligand, ${ }^{12}$ with $\mathrm{N}-\mathrm{C}$ distances of $c a .1 .34 \AA$, and $\mathrm{C}-\mathrm{C}$ bond lengths ranging from $1.364(5)$ to $1.387(4) \AA$ for the terminal ring, and 1.378(4) to $1.395(4) \AA$ for the central ring. Similar considerations apply to the central ring of the terpy ligand in binuclear complex 3 . However, the coordinated rings of the two compounds have metric parameters that show significant deviations with respect to the free ligand. Thus, referring to diiridium complex $\mathbf{3}$, the two $\mathrm{C}-\mathrm{N}$ distances become somewhat longer (for the $\mathrm{N}(13)$ ring they have values of $1.379(10)$ and $1.391(10) \AA$ ), and there

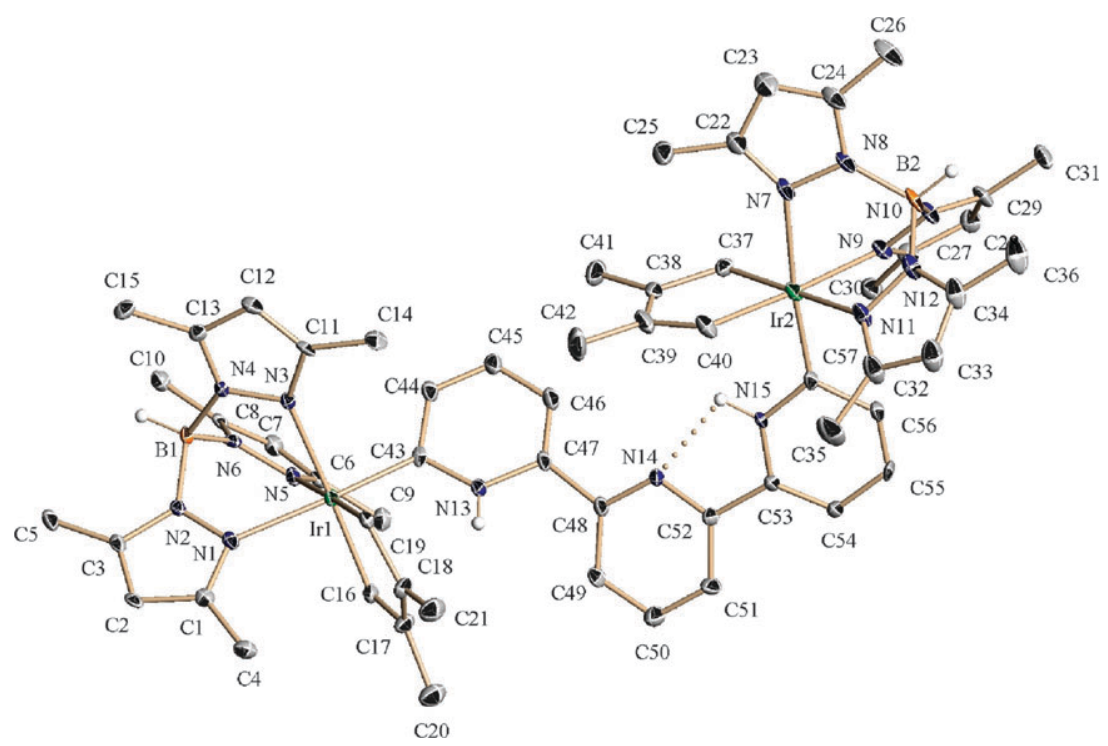

Fig. 2 Molecular structure of binuclear carbene 3 with terpy acting as a bridging bidentate carbene. Thermal ellipsoids are plotted at the $30 \%$ probability level. Hydrogen atoms and the non-coordinating tetrahydrofuran molecule are omitted for clarity. 
is some alternation in the $\mathrm{C}-\mathrm{C}$ bonds, as shown for instance by the following set of values: $\mathrm{C}(43)-\mathrm{C}(44)=1.433(11)$; $\mathrm{C}(44)-\mathrm{C}(45)=1.348(11) ; \mathrm{C}(45)-\mathrm{C}(46)=1.392(11)$ and $\mathrm{C}(46)-\mathrm{C}(47)=1.336(11) \AA$.

As already mentioned, the NHC-type coordination of terpy demonstrated for $\mathbf{2}$ and $\mathbf{3}$, in the solid state, by X-ray diffraction studies is also maintained in solution. In the IR spectrum a broad band is found at $c a .3225(2)$ and $3175(3) \mathrm{cm}^{-1}$, which is due to the stretching of the $\mathrm{N}-\mathrm{H}$ bond. The two complexes present a broad resonance in the ${ }^{1} \mathrm{H}$ NMR spectra at $c a .11 .8 \mathrm{ppm}$, which is also associated with the $\mathrm{N}-\mathrm{H}$ group of their respective carbene linkages, while in the ${ }^{13} \mathrm{C}\left\{{ }^{1} \mathrm{H}\right\}$ NMR spectra the carbene carbon nuclei resonate in the proximity of $186 \mathrm{ppm}$. NOE experiments that are detailed in the $\mathrm{ESI} \dagger$ reveal that the solid state structure of $\mathbf{2}$ shown in Fig. 1 is the preferred one in $\mathrm{CDCl}_{3}$ solution. Interestingly, although the NOESY spectrum of compound $\mathbf{3}$ indicates that the structure shown in Fig. 2 is maintained in solution $\left(25^{\circ} \mathrm{C}, \mathrm{CDCl}_{3}\right)$, the conformational flexibility of terpy permits the creation of an effective mirror plane in solution that makes the two Ir-carbene termini equivalent. To complete the solution characterization of $\mathbf{2}$ and $\mathbf{3}$ their UV-Vis spectra have been measured (see spectroscopic data in ESI† and Fig. S2).

In summary, two new $\operatorname{Ir}(\mathrm{III})$ complexes of terpy, an outstanding ligand for a number of metal cations, have been prepared and demonstrated to contain terpy coordinated as a terminal, monodentate N-heterocyclic carbene (complex 2) or a bridging, bidentate $\mathrm{N}$-heterocyclic carbene (complex 3 ), both in solution and in the solid state.

This work was supported by the Spanish Ministry of Science and Innovation (MICINN; grants CTQ2007-62814 and Consolider Ingenio 2010 CSD2007-0006) and the Junta de Andalucía (group FQM 119) (FEDER support).

\section{Notes and references}

$\ddagger$ Single crystal data for 2 : $\mathrm{C}_{36} \mathrm{H}_{43} \mathrm{BIrN}_{9}, M_{\mathrm{w}}=804.80$, plate red crystal, size: $0.27 \times 0.18 \times 0.15 \mathrm{~mm}$, monoclinic, space group $P 2_{1} / n$, $a=12.0676(3) \AA, b=22.2040(7) \AA, c=13.7392(4) \AA$, $\beta=108.8360(10)^{\circ}, V=3484.25(17) \AA^{3}, T=173(2) \mathrm{K}, Z=4$, $D=1.534 \mathrm{Mg} \mathrm{m}^{-3}, \rho=3.872 \mathrm{~mm}^{-1}, F(000)=1616 ; 91260$ reflections measured, of which 10431 were unique $\left(R_{\text {int }}=0.0388\right)$. 435 refined parameters, final $R_{1}=0.0226$ for reflections with $I>2 \sigma(I), \mathrm{w} R_{2}=0.0533$ (all data), GOF $=1.041$. Final largest

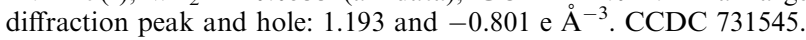
§ Single crystal data for 3: $\mathrm{C}_{61} \mathrm{H}_{83} \mathrm{~B}_{2} \mathrm{Ir}_{2} \mathrm{~N}_{15} \mathrm{O}\left[\mathrm{C}_{57} \mathrm{H}_{75} \mathrm{~B}_{2} \mathrm{Ir}_{2} \mathrm{~N}_{15} \cdot \mathrm{C}_{4} \mathrm{H}_{8} \mathrm{O}\right]$, $M_{\mathrm{w}}=1448.44$, plate red crystal, size: $0.11 \times 0.05 \times 0.03 \mathrm{~mm}$, triclinic, space group $P \overline{1}, a=10.9949(9) \AA, b=17.1764(14) \AA, c=$ 17.3819(14) $\AA$, $\alpha_{\circ}=104.057(2)^{\circ}, \beta=102.473(3)^{\circ}, \gamma=93.350(2)^{\circ}$, $V=3093.4(4) \AA^{3}, T=173(2) \mathrm{K}, Z=2, D=1.555 \mathrm{Mg} \mathrm{m}^{-3}$, $\rho=4.351 \mathrm{~mm}^{-1}, F(000)=1452 ; 40562$ reflections measured, of which 12549 were unique $\left(R_{\text {int }}=0.0967\right)$. The asymmetric unit of the structure is formed by one binuclear $\operatorname{Ir}(\mathrm{III})$ complex $\mathbf{3}$ and one solvation THF molecule. The solvent THF molecule was observed to be disordered in two positions. The sites occupancy factors for these two disordered moieties were first refined and the latest stages of refinement, due to the convergence, were both fixed to 0.5 . All the non-hydrogen atoms were refined with anisotropic displacement parameters. The hydrogen atoms bonded to the nitrogen atoms were located from the difference Fourier synthesis and refined isotropically with geometric restraints. The other hydrogen atoms were placed in calculated positions and refined with isotropic displacement parameters by using a riding model. 797 refined parameters, final $R_{1}=0.0498$ for reflections with $I>2 \sigma(I), \mathrm{w} R_{2}=0.1021$ (all data), $\mathrm{GOF}=1.001$. Final largest diffraction peak and hole: 1.437 and -1.205 e $\AA^{-3}$. CCDC 731547 .

1 (a) E. C. Constable, Adv. Inorg. Chem. Radiochem., 1986, 30, 69; (b) E. C. Constable, Prog. Inorg. Chem., 1994, 42, 67; (c) A. Harriman and R. Zressel, Coord. Chem. Rev., 1998, 171, 331.

2 U. S. Schubert, H. Hofmeir and G. R. Newkome, Modern Terpyridine Chemistry, Wiley-VCH Verlag GmbH \& Co. KGaA, Weinheim, 2006.

3 (a) S. H. Wiedemann, J. C. Lewis, J. A. Ellman and R. G. Bergman, J. Am. Chem. Soc., 2006, 128, 2452; (b) J. C. Lewis, R. G. Bergman and J. A. Ellman, Acc. Chem. Res., 2008, 41, 1013.

4 (a) M. A. Huertos, J. Pérez, L. Riera and A. Menéndez-Velázquez, J. Am. Chem. Soc., 2008, 130, 13530; (b) M. A. Huertos, J. Pérez and L. Riera, J. Am. Chem. Soc., 2008, 130, 5662.

5 (a) M. A. Esteruelas, F. J. Fernández-Alvarez and E. Oñate, J. Am. Chem. Soc., 2006, 128, 13044; (b) M. L. Buil, M. A. Esteruelas, K. Garcés, M. Oliván and E. Oñate, J. Am. Chem. Soc., 2007, 129, 10998; (c) M. A. Esteruelas, F. J. Fernández-Alvarez and E. Oñate, Organometallics, 2007, 26, 5239.

6 S. Burling, M. F. Mahon, R. E. Powell, M. K. Whittlesey and J. M. J. Williams, J. Am. Chem. Soc., 2006, 128, 13702.

7 (a) J. Ruiz and B. F. Perandones, J. Am. Chem. Soc., 2007, 129 , 9298; (b) J. A. Cabeza, I. del Río, E. Pérez-Carreño, M. G. Sánchez-Vega and D. Vázquez-García, Angew. Chem., Int. Ed., 2009, 48, 555.

8 (a) G. Song, Y. Li, S. Chen and X. Li, Chem. Commun., 2008, 3558; (b) G. Song, Y. Zhang, Y. Su, W. Deng, K. Han and X. Li, Organometallics, 2008, 27, 6193; (c) A. Poulain, A. Neels and M. Albrecht, Eur. J. Inorg. Chem., 2009, 1871; (d) M. Matena, T. Riehm, M. Stöhr, J. A. Jung and L. H. Gade, Angew. Chem. Int. Ed., 2008, 47, 2414.

9 (a) S. Conejero, P. Lara, M. Paneque, A. Petronilho, M. L. Poveda, O. Serrano, F. Vattier, E. Alvarez, C. Maya, V. Salazar and E. Carmona, Angew. Chem., Int. Ed., 2008, 47, 4380; (b) E. Alvarez, S. Conejero, P. Lara, J. A. López, M. Paneque, A. Petronilho, M. L. Poveda, D. del Río, O. Serrano and E. Carmona, J. Am. Chem. Soc., 2007, 129, 14130; (c) E. Alvarez, S. Conejero, M. Paneque, A. Petronilho, M. L. Poveda, O. Serrano and E. Carmona, J. Am. Chem. Soc., 2006, 128, 13060.

10 (a) F. P. Pruchnik, F. Robert, Y. Jeannin and S. Jeannin, Inorg. Chem., 1996, 35, 4261; (b) A. A. Sidorov, G. G. Aleksandrov, E. V. Pakhmutova, A. Yu. Chernyad'ev, I. L. Eremenko and I. I. Moiseev, Russ. Chem. Bull., 2005, 54, 588; (c) T. Koizumi, T. Tomon and K. Tanaka, Organometallics, 2003, 22, 970.

11 (a) O. Boutry, M. L. Poveda and E. Carmona, J. Organomet. Chem., 1997, 528, 143; (b) M. Paneque, M. L. Poveda, V. Salazar, E. Gutiérrez-Puebla and A. Monge, Organometallics, 2000, 19, 3120

12 (a) C. A. Bessel, R. F. See, D. L. Jameson, M. R. Churchill and K. J. Takenchi, J. Chem. Soc., Dalton Trans., 1992, 3223; (b) K. F. Bowes, I. P. Clark, J. M. Cole, M. Gourlay, A. M. E. Griffin, M. F. Mahon, L. Ooi, A. W. Parker, P. R. Raithby, H. A. Sparkes and M. Towrie, CrystEngComm, 2005, 7, 269.

13 G. R. Desiraju and T. Steiner, The Weak Hydrogen Bond, Oxford University Press, Oxford, 1999. 